\title{
Being transparent or spinning the message? An experiment into the effects of varying message content on trust in government
}

\author{
Stephan Grimmelikhuijsen \\ Utrecht University, Utrecht School of Governance, Bijlhouwerstraat 6, 3511 ZC Utrecht, The \\ Netherlands \\ Tel.: +31 3025314 33; Fax: +31 3025372 00; E-mail: s.g.grimmelikhuijsen@uu.nl
}

\begin{abstract}
Computer-mediated transparency is widely acknowledged to be a powerful instrument to strengthen citizen trust in government. However, government websites are often used as a convenient way to spread 'spinned' policy messages with highly positive interpretations of government policies. This paper focuses on this particular element of transparency: the extent to which a policy message contains balanced information. A truly balanced message should also mention dissenting viewpoints of government policies. This study examines the effect on trust of a balanced message compared to messages subject to varying degrees of spin. An experiment was designed to compare the effect of a very positive policy message, a slightly positive message and a message containing both positive and negative information. The results demonstrate that a balanced message on a website about government policy leads to negative evaluations of government competence to solve policy problems. Further, less spin does not positively affect the perceived honesty and benevolence of a government organization. This study suggests that showing balanced content might not be helpful when it comes to increasing trust in government, and that people might even prefer a light form of spin on government information as it provides the image that government knows what it is doing and where it is heading.
\end{abstract}

Keywords: Websites, experiments, trust in government, policy transparency, spin

\section{Introduction}

Transparency is acknowledged to be a quintessential democratic value for a trustworthy, high performing and accountable government [21,31]. Besides being a value in itself, transparency is regarded to be a promising instrument to increase citizen trust in government $[41,53]$. Since high levels of trust in government and between people in society are considered to be essential for societies to prosper and for governments to functioning well, a lack of trust in government is one of the major concerns in contemporary governance $[18,23,27,33,45]$. There has been a longstanding normative debate whether transparency is the ideal manner to increase trust in government. 'Transparency optimists' argue that transparency will lead to a culture of openness and more trust in government, (e.g. [41]) whereas 'transparency pessimists' stress the negative effects such as politics of scandal and 'demystification' of government (e.g. [4]).

The rise of ICTs and the Internet has given new impetus to this debate. For example, the Internet allows information about government decision-making, policies or policy outcomes to be disclosed in new formats on unprecedented scale $[9,11,52]$. The backbone of transparency can be found in Freedom of Information Acts (FOIAs). These laws have enabled government transparency for many 
years and have been implemented in many countries throughout the world [47]. For example, the US already implemented a FOIA in 1966 and the Netherlands in 1980. Sweden takes pride in having the oldest FOIA, which already came into force in 1766. Recently, however, so-called 'computer-mediated transparency' has gained attention in the literature [39].

Websites are an important tool for transparency in this regard, and it provides an opportunity for government organizations to provide information pro-actively. In contrast, many government websites scream for attention to tell citizens what good work they do and what policy measures are carried out. It seems that government organizations a great deal of pay lip service to transparency, yet it is acknowledged that in general government websites are often used as a means to communicate with the public and spread rose-tinted press-releases about government policies [34]. According to Davis [12] the Internet is often used as a public relations rather than a public participation tool.

This is where transparency touches on spin. In recent decades the importance of information in societies has increased enormously. Transparency is one of the exponents of this information culture yet this pressure to be transparent has also pushed spin control towards the center stage of government [48] as a counter-pressure. Several tactics of spin exist to divert attention or to counter transparent information [20, 48]. Spin could also entail simply to lie or to craft a story containing highly positive interpret by valid statistics. One specific type of we will focus on is putting a particular and favorable interpretation on the information that is released.

Transparency thus not only regards whether some information is present, yet also what the content of this information is: to what extent is it subject to favorable interpretations of facts. A government organization can easily ignore certain facts and emphasize others that are more in line with their policy. This means that the actual content of information that is disclosed is crucial. Transparency does not only entail the mere fact that some information is present, yet also the extent to which this online message allows dissenting information. If the content of a message has not been subject to spin, it is thought to be more transparent. On the other hand, if a particular favorable interpretation is put on the information (thus more spin); transparency is less. Therefore, the actual content of a policy message will be the central focus of this study which leads to the following central question: What is the effect of varying spin of message content on citizen trust in a government organization?

This question is answered by carrying out an experiment $(\mathrm{N}=60)$ containing three groups, which vary on content. One experimental group received a policy message with two-sided information (i.e. both positive and negative information). Two other experimental groups received information with a favorable interpretation of the information: one had a slightly positive message, whilst the other had a highly positive message. This experimental design allows us to make actual causal inferences about the transparency and trust relationship. Several hypotheses are tested to shed light on the specific differences in trust between experimental groups. First, however, the debate and literature on transparency and trust are discussed in the next two sections.

\section{The debate on transparency and trust in government}

The introduction of this article stated that the potential effect of transparency is heavily debated in the literature. This section outlines two extreme positions in the debate: those who we might call transparency optimists and transparency pessimists. ${ }^{1}$

\footnotetext{
${ }^{1}$ Skeptics argue that there is no relationship between transparency and trust, and/or that in fact other factors determine citizen trust in government; this position will not be discussed further in this paper.
} 
Arguably the most famous transparency optimist is President Barack Obama who instigated the 'Open Government Directive.' One of his main arguments to be more transparent is, besides obvious political rhetorical reasons, to restore citizen trust in government. The point of view that transparency will increase trust is also pleaded by transparency advocates like Brin [6]. They ultimately see transparency as something good, having only a few perverse side effects which can be eliminated through proper implementation of transparency by governments. Transparency optimists emphasize that transparency is said to stimulate a 'culture of openness' within organizations, or at least the perception of having an open culture, which is supposed to have a positive effect on trust [26, p. 217]. Moreover, according to transparency proponents, 'lifting the veil of secrecy' will be beneficial to all of us and that only those who have something to hide will oppose transparency. Finally, transparency helps people to become more familiar with and knowledgeable about, government and to bring them closer and creating understanding $[2,3,8]$.

On the other hand, scholars argue that a greater degree of transparency generates the possibility to unjustly repeatedly blame the government for mistakes. Three common criticisms of transparency are mentioned in this section. First, scholars argue that transparency leads to a great deal of information, yet it does not mean this leads to increased levels of trust. The Internet makes it possible to disclose a great deal of information, which leads to an information overload [35] and a flood of misinformation [42]. This could consist of, indeed, various forms of spin, such as highly positive interpretations, irrelevant information or outright lies (e.g. [20,50]). Second, transparency pessimists stress that increased transparency could lead to increased blaming of government. According to scholars, a fault by government can always be construed, and if citizens, media and politicians use transparency for their own gain with no restraints, this could result in the 'politics of scandal' [4,48,53, pp. 575-576]. This is exemplified by the recent stir about the disclosure of ten thousands of cables by WikiLeaks. Mass media reported on several cables and other 'war logs' instigating bigger or smaller political scandals, political games or particular statements done by politicians. Some reports have been more serious (e.g. the deaths of Iraqi civilians and the American military appeared to be greater than the numbers made public) than others (e.g. American diplomats describing personalities of world leaders). Whatever one thinks of WikiLeaks, the disclosure of such events is unlikely to will not have a positive effect of trust in government. Third, Bovens [4] warns about another 'dark side of transparency: when people can see everything behind the scenes of government, they may become disenchanted with government. People notice that behind the scenes, government operations are not as rational as it appears from the outside. Increased information might expose limitations of what government can do, thus decreasing political trust [8, p. 398].

\section{Transparency and trust}

\subsection{Three dimensions of perceived trustworthiness}

Understanding why and how people trust has thus been the central focus of research for psychologists, sociologists, political scientists, economists and organizational scientists for many decades. Because of this multidisciplinary character, Rousseau et al. [49] tried to formulate an overarching definition of trust. Confident expectations and a willingness to be vulnerable [36] are critical components of all definitions. Based on these overarching elements, an influential definition by Rousseau et al. state that trust is 'a psychological state comprising the intention to accept vulnerability based upon positive expectations of the intentions or behavior of another' [49, p. 395]. This means that trust is viewed as the perceived trustworthiness of another. This concept is acknowledged by many scholars to be 
multidimensional [36,38,40,49, p. 395]. In this paper, three dimensions of perceived trustworthiness are distinguished: competence, benevolence, and honesty.

First, many authors on trust find some form of perceived competence to be a part of trustworthiness. Some call it 'ability' [28], 'effectiveness' [23] or 'expertise' [43]. Yet the differences in meaning are small, as they all refer to some kind of capability to act. In this paper, this refers to whether people perceive a government organization to be capable, effective, skilful or professional in making decisions.

Second, many scholars regard perceived benevolence to be a part of trustworthiness. This can be viewed as an ethical dimension of trustworthiness; it particularly focuses on the intentions of government action. Some authors call this dimension 'care' [43], 'commitment' [33] or 'concern' [40]. For this study, this refers to whether people think that a government organization genuinely cares about the citizens living in their municipality.

Third, many scholars identify perceived honesty or integrity of the trustee. In this paper, perceived honesty implies that the government organization is perceived to keep commitments and tell the truth [29, 37]. Now that the concept of perceived trustworthiness has been made clear, the next section elaborates on the definition and concept of transparency.

\subsection{Transparency: Watching government from the outside}

Transparency has been discussed already in a general sense; this section will provide a more detailed definition. First, several 'directions' of transparency have been distinguished by Heald [22]. $\mathrm{He}$ argues that transparency can be directed outwards (government observing citizens), inwards (citizens observing government), upwards (subordinates observe their supervisors) and downwards (supervisors observe subordinates), or any combination of these. This article focuses on the 'inward' dimension of transparency. Most definitions of transparency recognize the extent to which an entity reveals relevant information about its own decision processes, procedures, functioning and performance $[9,19,52]$. As such, transparency typically incorporates multiple components including the availability of information about the internal workings or performance of an organization. This enables 'inward observability', which refers the ability of individuals and groups outside of the organization to monitor activities and decisions undertaken within the organization. In this paper transparency is defined as follows:

Transparency is the availability of information by an organization or actor allowing external actors to monitor the internal workings or performance of that organization.

In the past, scholars interested in computer-mediated government transparency have developed measurement instruments that focus on the technical aspects of government websites. Most prominently, the Cyberspace Policy Research Group developed a Website Attribute Evaluation System (WAES) which has been widely used $[13,32,44]$. More recent research research has shown that transparency can be distinguished by separate events and processes of government. This study adapts a model by Heald [22] by identifying the following steps: 1) transparency of decision making processes; 2) transparency of policy content; and 3) transparency of policy outcomes or effects. As government makes decisions about policy, it engages in a process in which problems are presented, potential solutions are identified and choices are made given constraints and opportunities that exist at that point in time. Decision making transparency contains two subtypes: the degree of openness about the steps taken to reach a decision and the rationale behind the decision. Decisionmaking transparency has been more extensively conceptualized and operationalized by Drew and Nyerges [15]. Policy transparency refers to the information disclosed by government about the policy itself: what the adopted measures are, how they are supposed to solve a problem, how they will be implemented and what implications they will have for citizens and 
other affected groups. Finally, policy outcome transparency captures the provision and timeliness of information about policy effects.

Besides these objects of transparency, several dimensions of the information that is made transparent can be distinguished. Information completeness refers to whether the information is disclosed fully. To what extent is all information laid out and disclosed [15]? The usability of information is also important. In stead of just divulging more information, transparency also implies that information is disclosed in a timely matter and presented in an understandable format (e.g. [22]). The content of information refers to the coloring of the information and will be explained further in the next section.

In this paper is focused on policy transparency and the content of the information disclosed by this transparency. This combination is particularly interesting since policy information disclosure is hardly enforced and therefore government organizations have a great deal of leeway in the content of the policy information they disclose. This results in varying degrees of transparency and spin on websites [21]. Therefore policy transparency is one of the main targets for government spin and thus crucial to improve our understanding of the various effects of message content. The next section explains how the content of policy transparency and spin are related.

\subsection{Spin and transparency}

We now know what transparency is and how it is conceptualized in this paper. However, there is a grey area in which the content of a message is transparent to the extent to which negative content is also allowed, instead of only positive stories. This section aims to shed more light on this grey area, by first elaborating on the concept of spin.

Spin of information can be distinguished by two main types. Spin might be focused on making oneself look better to the public. One can try to weaken negative stories or to emphasize positive stories. This will be labeled 'untargeted spin' since the spin is not targeted towards someone or something else. The second main type of spin is 'targeted' towards for example opponents and is mainly observed in the political arena. In other words targeted spin is aimed to make opponents look worse or less positive. In this paper we focus on untargeted spin.

Several tactics of spin are possible then, to put the targeted or untargeted spin into practice. Snell [50] and Gaber [20] mention several spin tactics. 'Pre-empting' is the first of tactics and regards the confirmation of the substance of a story before the actual details are confirmed in order to diminish the impact of the negative news. Second, 'diversion' is an important spin tactic. For example, throw about bad news on days that other stories will surely dominate the news. Another form of diversion is 'laundering': running a good news story running along a bad news story. Third, a part of any effective spin strategy is the 'manipulation' of journalists. This manipulation can take more or less subtle forms. For example, creating 'in-group' of journalists who are given access to sources of information and exclusive stories, and an 'out-group' that is excluded or even bullied. Fourth, there is the 'crafting of stories'. The crafting of a (policy) story entails releasing information with favorable and positive interpretation of certain facts or statistical data. The previous section already mentioned that this paper focuses on the content of policy transparency. How does this relate to the several spin tactics mentioned here? Figure 1 shows their relationship.

A message on a government website might present a full picture of their policies, allowing negative content. They might also try to ban out all negative content and show a 'polished' version of their policy. This is considered to be a form of spin by government which concerns the deliberate presentations highly positive policy information without leaving any room negative interpretations (cf. [50]). 


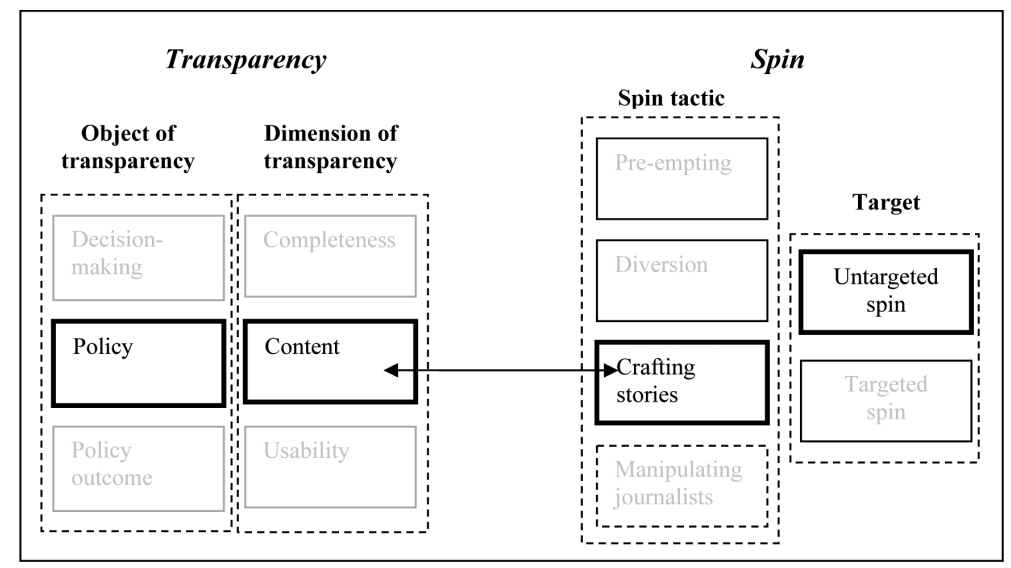

Fig. 1. The relationship between transparency and spin in this paper.

Focusing on the content of information raises the issue about how to assess the degree of balance of the content of a message. When is a balanced picture of a policy presented? This might be the case if it also allows negative content including dissenting views on this policy. On the other hand there might be instances of policy that are just very efficient and produce desired effects. For example, negative information might not be there if a municipality has implemented policy measures to combat air pollution that are working perfectly.

The abovementioned touches on a problem in assessing the content of policy transparency: we need to know what happened 'in reality'. Moreover, in the public realm this often entails a political reality in which facts are ambiguous and open to multiple interpretations [51]. One and the same issue can be portrayed in very different ways. For example, a government organization could state: 'extensive measurement by an independent research bureau shows that in 2015, our city will be one of cleanest in the country.' On the other hand, the abovementioned message could be represented by providing balanced information: 'Although no definitive conclusions can be drawn concerning the exact profits of the policy measures, measurements of an independent research bureau make clear that our policy might lead to slight improvements in the quality of the air in our city.'

Hence, what is 'true' is hard to determine, especially in a political context. Yet the degree of balance can be assessed and does probably (though not necessarily) relate to the degree of veracity of a policy message. Scholars seem to agree that information on government websites tends to be overly positive about government policies, actions or officials $[12,16,34]$ and that presenting messages with overly positive interpretations to compensate negative messages is a common form of spin $[20,50]$. This means that the content of a message is transparent to depend on the extent to which negative content and dissenting views are allowed, instead of only highly positive stories.

\section{Hypotheses}

Despite the general consensus that trust and transparency are multidimensional concepts, the debate on transparency and trust is mainly discussed on a general level. This means that no specific cues are given as to what elements of perceived trustworthiness are affected by transparency. A large body of literature argues that mainly positive effects of transparency on trust are expected $[1-3,6,17,26]$. On the other hand, there are scholars who point at the negative effects of transparency (e.g. $[4,16,42])$. For example, 
it could lead to politics of scandal or misinformation which could eventually lead to less instead of more trust. However, because the discourse on transparency tends to be overly positive, we will put this view to the test by postulating two positive hypotheses regarding the effect of policy transparency on perceived trustworthiness. The 'transparency pessimist' literature is acknowledged in the first hypothesis, which postulates a negative effect of transparency.

\section{H1: A higher degree of message balance is expected to negatively affect perceived competence.}

In general, transparent government information brings out information that is not necessarily positive. With regard to policy transparency, providing more negative message content shows the municipality's shortcoming and uncertainties regarding policy measures. Although it is expected that this positively impacts perceived honesty, this might come at the cost of lower levels of perceived competence.

\section{H2: A higher degree of message balance is expected to positively affect perceived benevolence.}

Perceived benevolence is expected to be positively affected by a high level of transparency. Benevolence concerns the intentions of a government organization, i.e., its willingness to act in the interest of its citizens. If the government is willing to give us transparent policy information, i.e. information that incorporates two sides of the story (positive and negative), it expected to appear to be more benevolent than a government organization which releases information with a particular positive interpretation.

\section{H3: A higher degree of message balance is expected to positively affect perceived honesty.}

Third, perceived honesty is expected be positively affected. Disclosing two-sided policy information, gives a more encompassing image of policy measures taken by local government. It is expected that by allowing also negative policy information government organization increases the perception that the municipality has been fully honest: they give the impression there is nothing to hide.

\section{Data and method}

\subsection{Experimental context: Environmental policy in Dutch local government}

An experiment was used to test the effect of transparency of a government organization on trust in this government organization. Experiments are widely used by social psychologists, but they often study concepts abstracted from reality. One can question whether this abstract method works for public administration research. Bozeman and Scott [5, p. 309] argue that laboratory experiments in public administration research should require attention to "mundane reality". This means there should be sufficient levels of contextual realism in experiments in order to be able to use the results in public administration practice. In this dissertation an experimental design is used with preservation of a degree of realism. The situation of a citizen that wants to obtain information about how his/her municipality deals with air pollution is chosen as the context for the experiments.

Why was this context chosen? By selecting a specific municipality instead of trust in government in general, the relationship between transparency of this government organization and trust in this government organization is isolated from exogenous factors that might play a prominent role concerning trust in government in general. More specifically, municipalities are selected because these are also 
thought to be a most likely case design. Since the effect of transparency on trust is far from proven, we need to search for a case where this connection is most probable. A municipality is thought to be a "most likely case" since it is well-known to most citizens; they are the most contacted government organization on the Internet [14] and have ties closest to citizens [44,46].

Further, the experiment's context is comprised by the issue of air pollution policy. Air pollution is of special interest as it affects citizens' lives, not only in terms of where buildings and roads are constructed, but also their health. In addition, environmental issues are important to transparency as this is prescribed in treaties and legislation. Governments in Europe are obliged to meet EU directives about air quality, ${ }^{2}$ and local governments in the Netherlands are obliged to develop plans to combat air pollution.

In addition, the Dutch Freedom of Information Act and the Aarhus Treaty requires countries to provide environmental information to the public. What kind of information is required exactly is not made clear by the treaty, which gives government organizations much leeway to design the content of their websites. As a consequence, local governments have a great deal of discretion to put online particular interpretations of policies that are favourable to them (i.e. spin). Issues of air pollution and the environment have been prominent in government transparency policies for many years since disclosure of data about air pollution in cities in the EU and the US nowadays is common practice.

\subsection{Design}

To examine the effect of transparency on trust, this study used an independent one-way experimental design. This means that three groups of participants were used in the experiment and were separately investigated on one independent variable. The three groups varied on the degree of the content of transparency, ranging from a message with negative, positive and very positive cues.

In the experiment presented in this paper, a transparent message shows a two-sided picture of the municipality's air pollution policy measures. This means that also ineffectiveness and the uncertainty of the effects of policy measures are mentioned. In addition to this group, there is one group receiving slightly positive information and finally a group receiving very positive information which does not fully correspond with reality. The dependent variables were the three dimensions of perceived trustworthiness: perceived benevolence, perceived competence and perceived honesty.

\subsection{Sample}

The sample consisted of a total of 60 participants, including first-year college students, and a group of graduate students. The design and group distribution is shown in Table 1. Generally speaking, the most important background variables that might affect trust in government are gender, age, education, and political preference. Males are said to be slightly more distrusting whereas left-wing voters in general have more trust in government. Age is also thought to have a negative effect on trust in government, whereas the level of education has a positive effect. People with higher levels of education tend to be more trusting towards government (for example see [7,10,30,41,45]).

Since only students were selected in the sample, there is no variance on both the level of education and hardly any variance on the age of the participants. Three variables are mentioned in Table 1 are those that might influence trust in a specific government organization, and hence that might distort the relationship between transparency and trust.

\footnotetext{
${ }^{2}$ For more details on the standards these directives have set out: http://ec.europa.eu/environment/air/quality/standards.htm (accessed Feb 24, 2010).
} 
Table 1

Sample composition

\begin{tabular}{|c|c|c|c|}
\hline & $\%$ male & Av. Age & Pol. Pref (\% l.w.) \\
\hline $\begin{array}{l}1-\text { Balanced Message } \\
\mathrm{N}=21\end{array}$ & 52.4 & $19.9(1.9)$ & 23.8 \\
\hline $\begin{array}{l}2 \text { - Slightly Positive Message } \\
N=18\end{array}$ & 27.8 & $19.9(2.1)$ & 38.9 \\
\hline $\begin{array}{l}3 \text { - Very Positive Message } \\
\mathrm{N}=21\end{array}$ & 45.5 & $20.1(2.1)$ & 31.8 \\
\hline $\begin{array}{l}\text { Total } \\
\mathrm{N}=60\end{array}$ & 42.6 & $20.0(2.0)$ & 31.1 \\
\hline
\end{tabular}

At first glance political preference and gender are not spread equally amongst the groups. Males are underrepresented in group 2, whereas participants with a leftwing political preference are underrepresented in group 1. To see whether these apparent differences in distribution are large enough to be significant, a Pearson chi-square test using crosstabs was carried out. These tests showed no evidence for an unequal distribution of gender, age, education or political preferences amongst the groups. ${ }^{3}$ This means that the randomization of participants in the experiment was successful, since differences in distributions of background variables are probably due to pure chance.

\subsection{Materials and procedure}

Every participant was randomly assigned to one of the groups by a link to a website on their written instruction form. Group 1 was assigned to fill out a questionnaire after visiting a government website containing a message with both positive and negative information about the municipality's policy measures. The slightly positive message group (group 2) and the highly positive information group (group 3 ) visited websites with similar layout, differing only on the content of transparency.

Before the experiment started, all participants were instructed orally about what they could expect. They were told that they were participating in a study to investigate the user-friendliness of government websites, instead of the real goal of the study (i.e. investigating the effect of transparency on trust). Finally, they were instructed to fill out an online questionnaire. Only after the experiment was finished the actual goal of the experiment was revealed to the participants.

\subsection{Measures}

Three dimensions of perceived trustworthiness were distinguished and separately measured. Participants were asked specifically about the perceived benevolence, competence, and honesty of the government organization with regard to the topic (air quality policy).

All dimensions were measured on a five-point scale and are derived and adapted from past research [37]. Benevolence was measured by the extent to which the government organization was perceived to be doing its best to help citizens (1), to be acting in the interest of citizens (2), and to be sincerely interested in the well-being of citizens (3). The Cronbach's alpha for this dimension was 0.84 . An alpha of 0.60 or higher

\footnotetext{
${ }^{3}$ Gender Pearson $\left(\mathrm{chi}^{2}=2.51, \mathrm{df}=2, p=0.285\right)$, Age (Pearson $\left.\mathrm{chi}^{2}=14.27, \mathrm{df}=14, p=0.430\right)$, Political preference (Pearson $\left.\mathrm{chi}^{2}=9.44, \mathrm{df}=2, p=0.624\right)$.
} 
Table 2

Summary of operationalization of message content

\begin{tabular}{|c|c|c|}
\hline Message & What & Example \\
\hline Balanced Message & $\begin{array}{l}\text { The balanced message contained both } \\
\text { positive and negative information. } \\
\text { Hence, also negative information on } \\
\text { government policy was allowed }\end{array}$ & $\begin{array}{l}\text { "Unfortunately, these policy } \\
\text { measures did not yet lead to the } \\
\text { desired improvement of the air } \\
\text { quality in [city name]." }\end{array}$ \\
\hline Slightly Positive & Information is generally positive on & "These policy measures have \\
\hline Message & $\begin{array}{l}\text { government policy. However, it leaves } \\
\text { room for a negative interpretation of } \\
\text { the text ('substantial improvement') yet } \\
\text { represented so as that it is optimistic } \\
\text { towards the policy problem in the } \\
\text { municipality }\end{array}$ & $\begin{array}{l}\text { led a substantial improvement } \\
\text { of the air quality in [city name] } \\
\text { already." }\end{array}$ \\
\hline $\begin{array}{l}\text { Very Positive } \\
\text { Message }\end{array}$ & $\begin{array}{l}\text { The very positive message leaves no } \\
\text { room for a negative interpretation of the } \\
\text { text since the policy measures are said } \\
\text { to be very effective and have led to a } \\
\text { very clean air. }\end{array}$ & $\begin{array}{l}\text { "These policy measures have } \\
\text { led to very clean air in [city } \\
\text { name] and have solved nearly } \\
\text { all problems with air quality on } \\
\text { the most polluted areas in [city } \\
\text { name]. }\end{array}$ \\
\hline
\end{tabular}

is considered to be sufficient to group items into one dimension. Competence was measured by the extent to which the government organization was perceived to be capable, effective, skilful and professional $($ Cronbach's alpha $=0.85)$. Honesty was measured by perceived sincerity, perceived honesty and the extent to which the government organization was thought to honour its commitments (Cronbach's alpha $=0.77$ ).

Message content of policy transparency was operationalized as follows. One message presented policy measures including negative cues. A second message was designed to be a subtly positive message, in which facts were strategically presented though the data itself was still accurate. A third message contained very optimistic pronouncements about government measures regarding air pollution.

An existing text about policy measures on a municipal website was the point of departure for this study's message. This text already contained subtly positive message content, so the existing message remained unaffected for this group. To create a two-sided message, negative arguments were added to the text, whereas to create the overly positive message the existing message was embroidered. The procedure to create these three messages was as follows. As mentioned, an existing and thus realistic policy text was used as the point of departure. This text was adjusted by the researcher for the purposes of this study. The messages were all discussed with several colleague researchers regarding whether they fitted their description (balanced/slightly positive/very positive message) and whether they could realistically exist on a government website. In other words, the message should be convincing, i.e. participants should believe that these message are actually available on a municipal website. Every message was tested and discussed multiple times with multiple colleagues and adjusted if necessary until no disagreement about the messages was left. Its operationalization and three exemplary excerpts are shown in Table 2. The structure of each message followed a similar pattern to make sure they were comparable. Further, the full text of each message consists of three paragraphs, but since it would take up too much text to display the full texts of each experimental group in this chapter, they are not displayed here. ${ }^{4}$

\footnotetext{
${ }^{4}$ The messages presented to participants are originally in Dutch. The original or translated messages are sent on request.
} 


\subsection{Checking the experimental manipulation}

Before attempting any further analysis the experimental set up was checked. In other words, do participants perceive the experimental treatment in the way the researcher intended? This analysis showed that participants perceived the website in the same way that the researcher did. The item 'the website of the municipality contained highly positive information' had a mean score of 2.95 on a fivepoint scale, running from one (totally disagree) through five (totally agree). The participants in the slightly positive experimental group gave this item a 3.78 on average. The highly positive group agreed even more with this item 4.17. A one-way ANOVA analysis that the differences in means are both significant $(\mathrm{F}(2,57)=10.94, p<0.01)$. This means that the negative, slightly positive and very positive messages were indeed perceived as such by the participants in the experiment.

\section{Results}

The hypotheses are tested by carrying out a one-way multivariate analysis of covariance (MANCOVA) ${ }^{5}$ This statistical technique is used to compare the results between the three levels of transparency on the three dimensions of perceived trustworthiness. The goal of this analysis is to carry out a group comparison to assess specific significant differences between each of the experimental groups. Before arriving at the pairwise group comparison the analysis follows three steps. The overall multivariate effect on all three dimensions of perceived trustworthiness is tested first. Next the analysis delves into univariate effects on each dimension of perceived trustworthiness separately. The overall multivariate effect indicates whether some significant difference occurs in the data, without specifying the effect. Univariate significance proves an effect in a particular dimension, for example perceived honesty. The pairwise group comparison then, brings forward significant differences between the experimental groups.

First, the overall multivariate effect of the content of transparency on all three dependent variables perceived benevolence, competence and honesty - indeed appeared to be significant $(F(2,57)=2.14$, $p=0.055$, eta $^{2}=0.108$ ). The subsequent analysis prescribes to test the effects of transparency on the three dimensions of perceived trustworthiness separately. This analysis shows that only a significant univariate effect of transparency is found on perceived competence $\left(\mathrm{F}(2,57)=2.66, p<0.1\right.$, eta ${ }^{2}=$ $0.090){ }^{6}$

We now proceed to test specific group differences in perceived trustworthiness (Hypotheses 1,2 and 3). To test every possible group comparison, post-hoc tests with Sidak-corrections for multiple comparisons were carried out. The results are displayed in Table 3 below. If means have a superscript in common within rows, no statistical difference was found between those groups. Means within rows with deviating superscripts are statistically different from each other at a level of $p<0.1$.

No group differences are found regarding perceived benevolence and honesty. This contradicts hypotheses $\mathrm{H} 2$ and $\mathrm{H} 3$, which predicted positive effects of transparency on benevolence and honesty.

\footnotetext{
${ }^{5}$ Multiple covariates are taken into account in the equation: message credibility, specific knowledge and trust in government in general. Message credibility and people's knowledge about a government organization are mediating variables through which transparency also leads to altered levels of perceived trustworthiness. The mediated effects will not be discussed in this paper, here we will only focus on the direct effect of transparency.

${ }^{6} \mathrm{~A}$ significance level of $p<0.1$ is used. This was considered to be appropriate, because of the relatively low number of participants in each experimental group. It should be noted that at this significance level, there is a probability of 10 percent that this results occurred by chance alone.
} 
Table 3

Group comparisons Perceived Benevolence, Competence, Honesty

\begin{tabular}{lccc}
\hline Dependent variable & $\begin{array}{c}\text { 1. Balanced } \\
\text { message }\end{array}$ & $\begin{array}{c}\text { 2. Slightly positive } \\
\text { message }\end{array}$ & $\begin{array}{c}2 . \text { Very positive } \\
\text { message }\end{array}$ \\
\hline Perceived Competence & $2.93(0.13)^{\mathrm{a}}$ & $3.34(0.14)^{\mathrm{b}}$ & $3.26(0.13)^{\mathrm{a}, \mathrm{b}}$ \\
Perceived Benevolence & $3.83(0.12)^{\mathrm{a}}$ & $3.46(0.13)^{\mathrm{a}}$ & $3.61(0.12)^{\mathrm{a}}$ \\
Perceived Honesty & $3.20(0.11)^{\mathrm{a}}$ & $3.03(0.12)^{\mathrm{a}}$ & $3.05(0.11)^{\mathrm{a}}$ \\
\hline
\end{tabular}

Means are displayed, standard errors in parentheses. $N=60$.

Rows with unequal superscripts differ significantly at $p<0.1$ with Sidak-correction for multiple comparisons.

Table 4

Summary of hypotheses

\begin{tabular}{lc}
\hline Hypothesis: & Result \\
\hline H1: A higher degree of message balance is expected to negatively affect per- & Accepted \\
ceived competence. & \\
H2: A higher degree of message balance is expected to positively affect per- & Rejected \\
ceived benevolence. & \\
$\begin{array}{l}\text { H3: A higher degree of message balance is expected to positively affect per- } \\
\text { ceived honesty. }\end{array}$ & Rejected \\
\hline
\end{tabular}

Hence, these hypotheses should be rejected: the content of policy transparency does not significantly affect the perceived honesty and benevolence of the municipality.

Another important observation from Table 3 is the group difference concerning perceived competence. People who read a message containing negative content about policy measures evaluate the government lower regarding its competence, compared to those who read a message with a slightly positive content. The average score on competence of group 1 (negative content) is even slightly below 3.0, which on a fivepoint scale is considered to be a neutral score. The two groups with slightly positive to highly positive content have considerably higher means on perceived competence. However, only group 2 (slightly positive) has difference large enough to result in a statistically significant effect. This is remarkable, because the very positive information left no room for a negative interpretation of the competence of the municipality.

The results of this section are summarized in Table 4, which restates the hypotheses and confirms whether or not they are accepted.

The direct effect of the content of policy information transparency only affects perceived competence (H1). A message that contained negative content indeed leads to lower judgements of competence. In contrast, no differences for perceived benevolence (H2) and perceived honesty (H3) occurred. Although a message with two-sided content presents a more transparent image of public policy, the municipality under scrutiny was not 'rewarded' by higher levels of perceived honesty or perceived benevolence. What implications does this have for our central question is discussed in the next section.

\section{Do people expect government information to be subject to spin?}

To answer the research question posed in the introduction of this paper, we conclude that this study found limited yet significant evidence for a negative effect of policy transparency on perceived trustworthiness. Only perceived competence was affected whereas other dimensions of perceived trustworthiness remained unaffected. Based on these results it remains questionable whether transparency will indeed lead to more trust in government. 
First, some limitations of the chosen experimental design regarding its external validity are discussed. The experiment contained a bias towards young and educated people (students) in the sample. Still, this might not be too problematic with respect to external validity, as Van Dijk et al [14] showed that people who use government websites are relatively young compared to the total population. Nevertheless, there might still be a bias on a higher level of analysis. This article specifically focuses on computer-mediated transparency, instead of other forms of transparency. Information provided through the Internet is likely to attract relatively highly educated citizens. Having said this, it should be noted that the main goal of this study - being an experiment - is not to achieve a perfect external validity, but to closely examine a theoretical effect by comparing relatively homogeneous groups while statistically controlling for possible extraneous variables.

A second limitation to this study is the limited number of participants in the experiment $(\mathrm{N}=60)$. A larger number of participants increases the power of the statistical test. This might have led to slightly more positive conclusions. For example, there was a rather large yet not significant positive effect of the transparent message with negative content on perceived benevolence of the municipality. Due to the relatively small study this conclusion cannot be drawn from the data. The lack of effect could be partly due to the nature of this experiment. People encountered the policy message only once for a short period of time. Further, it is unclear to what extent the negative effect on perceived competence lasts. Nevertheless, it is remarkable that such a short and single encounter with transparency already led to an effect on perceived competence. Future research should address these issue and aim for an experiment on a larger scale and other groups of citizens with other background characteristics, in order to increase the power and external validity of the statistical test.

The effect of a balanced message on perceived competence was negative compared to the message with slightly positive information. Do people just expect success stories of government then? On the one hand it seems that people in way do not want to know about these complexities and uncertainties. Results from the experiment offer some evidence that people might prefer to be appeased by a false image of that government knows what it is doing and where it is heading. Hibbing and Theiss-Morse [24,25] argue that people prefer a 'stealth democracy': people do not want to be involved in decision-making and they do not want to know about all the details of policy-making.

On the other hand, people do not seem to accept a mere success story. The slightly positive message gave rise to higher levels of perceived competence than the highly positive message, although one might expect the highly positive message to have a more positive effect on perceived competence. How could we interpret these results? The slightly positive content emphasized optimism about the policy measure implemented by the municipality left some room for a negative interpretation about their effectiveness. For example, it stated that 'substantial improvement' of the air quality has been attained by policy measures. The highly positive policy message did not leave this room and boldly stated that the air was clean already.

Thus, governments should be boasting too much about their policies. This study showed that leaving a little room for a negative interpretation about the government's policies was more effective than stating that policy measures are extremely effective and have easily attained their goals. Apparently being too bold about its own policy leads to somewhat less positive perceptions of the government organization. This means that the mere publishing of policy success stories do not pay off, yet more subtle forms of spin are accepted and maybe even expected. People prefer a government that knows what it is doing or at least portrays to the outside that it is.

How should we judge transparency as an instrument to increase trust in government? Based on this experiment, hardly any gains are expected on the level of an individual government organization. On 
an aggregated level, the system of government organizations a whole might benefit from transparency. Increased transparency is said to improve accountability arrangements of government [44]. Transparency is often mediated by 'third parties' (e.g. journalists, associations) to assess, scrutinize and provide feedback on government actions. This in itself might not be beneficial to trust; yet improved accountability mechanisms should prevent major errors or abuse of power which on the long term might benefit trust in government in general. Moreover, accountability and transparency are important democratic values in itself.

Overall, this study suggests that providing balanced message content might not meet the hopes of its advocates when it comes to increasing trust in government. Actual transparent and thus more balanced messages give rise to more critical evaluations of a government organization's competence. Government organizations seem to get away with policy messages that are slightly subject to spin. In the end providing information about one's policies with some positivism might provide people with the more secure feeling that government knows what it is doing and where it is heading.

\section{Acknowledgements}

The author would particularly like to thank Albert Meijer, Mark Bovens, Frank Bannister, Eva Knies, and the reviewers of this paper for their constructive and helpful comments on previous versions of this paper. A previous version of this paper was presented at the annual EGPA conference in Toulouse in 2010.

\section{References}

[1] P.J. Birkinshaw, Freedom of information and openness, fundamental human rights, Administrative Law Review 58(1) (2006), 177-218.

[2] R. Blendon, J. Benson, R. Morin, D. Altman, M. Brodie, M. Brossard and M. James, Changing Attitudes in America, in: Why People Don't Trust Government, J. Nye, P. Zelikow and D. King, eds, Cambridge, MA, Harvard University Press, 1997, pp. 205-216.

[3] D. Bok, Measuring the Performance of Government, in: Why People Don't Trust Government, J. Nye, P. Zelikow and D. King, eds, Cambridge, MA, Harvard University Press, 1997, pp. 55-75.

[4] M.A.P. Bovens, De Digitale Republiek: Democratie en rechtsstaat in de informatiemaatschappij, Amsterdam University Press, Amsterdam, 2003.

[5] B. Bozeman and P. Scott, Laboratory Experiments in Public Policy and Management, Journal of Public Administration Research and Theory 2(3) (1992), 293-313.

[6] G.D. Brin, The Transparent Society: will privacy force use to choose between privacy and freedom? Perseus, Reading MA, 1998.

[7] T.E. Cook and P. Gronke, The Skeptical American: Revisiting the Meanings of Trust in Government and Confidence in Institutions, The Journal of Politics 67(3) (2005), 784-803.

[8] F.L. Cook, L.R. Jacobs and D. Kim, Trusting What You Know: Information, Knowledge, and Confidence in Social Security, The Journal of Politics 72(2) (2010), 397-412.

[9] D. Curtin and A.J. Meijer, Does Transparency Strengthen Legitimacy? Information polity 11(2) (2006), 109-123.

[10] R. Dalton, Democratic Challenges, Democratic Choices. The Erosion of Political Support in Advanced Industrial Democracies, Oxford University Press, Oxford, 2004.

[11] Th. Davenport, Process Innovation: Reengineering Work through Information Technology, Boston: Harvard School Press, 1993.

[12] R. Davis, The Web of politics: The Internet's Impact on the American Political System, Oxford University Press, New York, 1999.

[13] C.C. Demchak, C.F. Friis and T.M. La Porte, Reflections on Configuring Public Agencies in Cyberspace: A Conceptual Investigation, In: Public Administration in an Information Age: A Handbook, I.T.M. Snellen and W.B.H.J. van de Donk, eds, IOS Press, Amsterdam, 2001, pp. 225-244. 
[14] J.A.G.M. van Dijk, O. Peters and W. Ebbers, Explaining the acceptance and use of government Internet services: A multivariate analysis of 2006 survey data in the Netherlands, Government Information Quarterly 25(3) (2008), 379-399.

[15] C.H. Drew and T.L. Nyerges, Transparency of environmental decision making: A case study of soil cleanup inside the Hanford 100 area, Journal of Risk Research 7(1) (2004), 33-71.

[16] A. Etzioni, Is Transparency the Best Disinfectant? The Journal of Political Philosophy (2010), early view (not yet indexed).

[17] A. Florini, Introduction: the battle over transparency, in: The Right to Know. Transparency for an Open World, A. Florini, ed., Colombia University Press, New York, NY, 2007, pp. 1-16.

[18] F. Fukuyama, Trust: The Social Virtues and the Creation of Prosperity, New York, Simon and Schuster, 1995.

[19] J. Gerring and S.C. Thacker, Political Institutions and Corruption: The Role of Unitarism and Parliamentarism, British Journal of Political Science 34 (2004), 295-330.

[20] I. Gaber, 'Lies, damn lies. .. and political spin', British Journalism Review 11(1) (2000), 60-70.

[21] S.G. Grimmelikhuijsen and E.W. Welch, A theoretical framework for government transparency. Factors affecting disclosure of environmental information of local governments in the Netherlands, paper presented at the annual EGPA conference, Toulouse, September 7-9, 2010.

[22] D. Heald, Varieties of Transparency, in: Transparency, The Key to Better Governance? C. Hood and D. Heald, eds, Oxford, Oxford University Press, 2006, pp. 25-43.

[23] M.J. Hetherington, The Political Relevance of Political Trust, The American Political Science Review 92(4) (1998), 791-808.

[24] J.R. Hibbing and E. Theiss-Moore, Stealth Democracy. American's Beliefs about How Government Should Work, Cambridge University Press, Cambridge, 2002.

[25] J.R. Hibbing and E. Theiss-Moore, Congress as Public Enemy. Public Attitudes toward American Political Institutions, Cambridge University Press, Cambridge, 1995.

[26] C. Hood, Beyond Exchanging First Principles? Some Closing Comments, in: Transparency, The Key to Better Governance? C. Hood and D. Heald, eds, Oxford, Oxford University Press, 2006, pp. 211-226.

[27] R. Inglehart, Trust, well-being and democracy, in: Democracy and trust, M.E. Warren, ed., Cambridge, Cambridge University Press, 1999, pp. 88-120.

[28] S.L., Jarvenpaa, K. Knoll and D.E. Leidner, Is anybody out there? Antecedents of trust in global virtual teams, Journal of Management Information Systems 14(4) (1998), 29-64.

[29] S. Kim, The Role of Trust in the Modern Administrative State, An Integrative Model, Administration and Society 37(5) (2005), 611-635.

[30] D.C. King, The Polarization of American Parties and Mistrust of Government, in: Why people don't trust government, J.S. Nye, P.D. Zelikow and D.C. King, eds, Cambridge: Harvard University Press, 1997, pp. 155-178.

[31] A.M. Kjaer, Governance, Malden, Polity Press, 2004.

[32] T.M. La Porte, National Differences in How Governments Use Web Sites, The Internet Connection: Your Guide to Government Resources, 1999.

[33] M. Levi and L. Stoker, Political Trust and Trustworthiness, Annual Review of Political Science 3 (2000), 375-507.

[34] J. Mahler and P.M. Regan, Crafting the message: Controlling content on agency Web sites, Government Information Quarterly 24(3) (2007), 505-521.

[35] H. Margetts, Transparency and Digital Government, in: Transparency, The Key to Better Governance?, C. Hood and D. Heald, eds, Oxford, Oxford University Press, 2006, pp. 197-207.

[36] R. Mayer, J.H. Davis and D. Schoorman, An Integrative Model of Organizational Trust, Academy of Management Review 20(3) (1995), 709-734.

[37] D.H. McKnight, V. Choudhury and C. Kacmar, Developing and Validating Trust Measures for E-commerce, An integrative Typology, Information Systems Research 13(3) (2002), 334-359.

[38] D.H. McKnight and N.L. Chervany, Reflections on an initial trust-building model, in: Handbook of Trust Research, R. Bachman and A. Zaheer, eds, Cheltenham, Edward Elgar Publishing, 2006, pp. 29-51.

[39] A.J. Meijer, Understanding computer-mediated transparency, International Review of Administrative Sciences 75(2) (2009), 255-269.

[40] A.K. Mishra, Organizational Responses to Crisis, The Centrality of Trust, in: Trust in Organizations, Frontiers of theory and Research, R.M. Kramer and T.R. Tyler, eds, Thousand Oaks, Sage, 1996, pp. 261-287.

[41] P. Norris, Digital Divide: Civic Engagement, Information Poverty, and the Internet Worldwide, Cambridge University Press, Cambridge, 2001.

[42] O. O'Neill, A Question of Trust, The BBC Reith Lectures 2002, Cambridge, Cambridge University Press, 2002.

[43] R.G. Peters, V.T. Covello and D.B. McCallum, The Determinants of Trust and Credibility in Environmental Risk Communication: An Empirical Study, Risk Analysis 17(1) (1997), 43-54.

[44] V. Pina, T. Lourdes and S. Royo, Are ICTs Improving Transparency and Accountability in the EU Regional and Local Governments? An Empirical Study, Public Administration 85(2) (2007), 449-472. 
[45] R. Putnam, Bowling Alone, The Collapse and Revival of American Community, New York, Simon and Schuster, 2000.

[46] S.J. Piotrowski and G.G. Van Ryzin, Citizen Attitudes Toward Transparency in Local Government, The American Review of Public Administration 37(3) (2007), 306-323.

[47] J.E. Relly and M. Sabharwal, Perceptions of Transparency of Government Policymaking: A Cross-National Study, Government Information Quarterly 26(1) (2009), 148-157.

[48] A. Roberts, Spin Control and Freedom of Information: Lessons for the United Kingdom from Canada, Public Administration 83(1) (2005), 1-23.

[49] D.M. Rousseau, S.B. Sitkin, R.S. Burt and C. Camerer, Not so Different after All: A Cross-Discipline View of Trust, The Academy of Management Review 23(3) (1998), 393-404.

[50] R. Snell, FOI and the Delivery of Diminishing Returns, or How Spin-Doctors and Journalists have Mistreated a Volatile Reform, The Drawing Board: An Australian Review of Public Affairs 2(3) (2002), 187-207.

[51] D. Stone, Policy Paradox, the Art of Political Decision Making, WW Norton \& Co, 2nd revised edition, 2002.

[52] E.W. Welch, E.W. Hinnant and M.J. Moon, Linking Citizen Satisfaction with E-government and trust in government, Journal of Public Administration Research and Theory 15(3) (2005), 371-391.

[53] B. Worthy, More Open but Not More Trusted? The Effect of the Freedom of Information Act 2000 on the United Kingdom Central Government, Governance: An International Journal of Policy, Administration, and Institutions 23(4) (2010), 561-582. 